\title{
Gilberto Velho
}

(1945-2012)

Tânia Welter ${ }^{l}$

Universidade Federal da Fronteira Sul/UFFS

Pedro Martins ${ }^{2}$

Universidade do Estado de Santa Catarina/UDESC

\section{O velho Gilberto: a influência de um mestre de muitas referências}

Gilberto Velho era, na verdade, ainda muito jovem quando deixou o campo, $\bigcup_{\text {em }} 15$ de abril de 2012, para viver em suas inúmeras fontes de referências construídas ao longo de sua carreira como antropólogo.

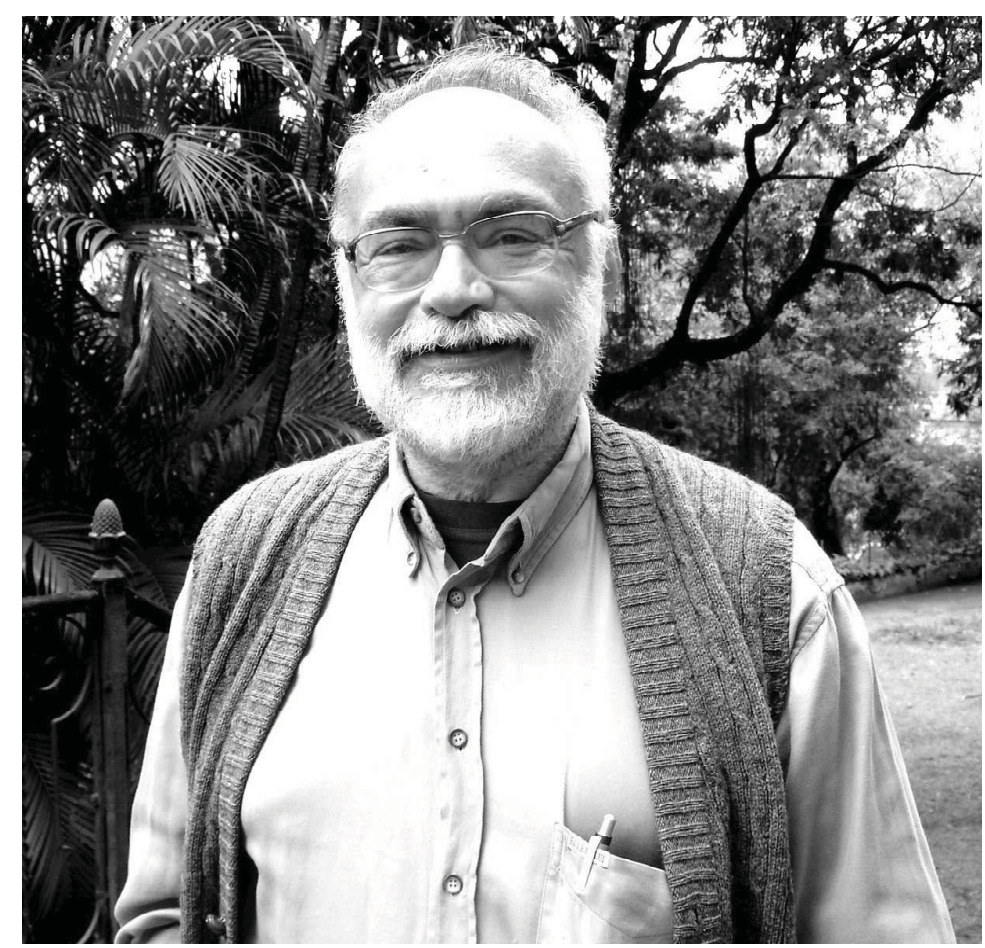

${ }^{1}$ Professora Adjunta da Universidade Federal da Fronteira Sul, campus Chapecó, coordenadora do Sub Projeto PIBID de Sociologia (CAPES/PIBID/UFFS), pesquisadora do Grupo de pesquisa Cultura, Política e Diversidade/UFFS. E pesquisadora também do Núcleo de Identidades de Gênero e Sexualidades/NIGS/ UFSC e do Grupo de Pesquisa Práticas Interdisciplinares em Sociabilidades e Territórios/PEST/UDESC. ${ }^{2}$ Professor da Universidade do Estado de Santa Catarina-UDESC, Sub-coordenador do Programa de Pós-Graduação em Planejamento Territorial e Desenvolvimento Socioambiental/ MPPT. Coordena o Grupo de Pesquisa Práticas Interdisciplinares em Sociabilidades e Territórios - PEST 


\section{HUMANAS}

Nascido em 15 de maio de 1945, bacharelou-se Cientista Social na Universidade Federal do Rio de Janeiro, em sua cidade natal. Mestre pela mesma UFRJ, Gilberto Velho foi doutorar-se na Universidade de São Paulo, antes tendo passado pela Universidade do Texas onde aproximou-se da antropologia urbana e do tema das sociedades complexas.

Mantinha vínculo institucional com o Museu Nacional da Universidade Federal do Rio de Janeiro desde 1969, tendo lá desenvolvido toda a sua carreira profissional. De lá partia como professor visitante para um grande número de outras instituições no Brasil e no exterior.

Até sua morte Gilberto Cardoso Alves Velho era decano do Departamento de Antropologia da UFRJ onde coordenou o Programa de Pós-Graduação em Antropologia Social. Entre muitas outras missões relevantes que desempenhou ao longo de sua carreira, assumiu a presidência da Associação Brasileira de Antropologia e da Associação Nacional de Pós-Graduação e Pesquisa em Ciências Sociais (ABA e ANPOCS), as mais importantes entidades científicas de sua área no país.

Tendo feito da antropologia urbana e do tema das sociedades complexas sua área de especialização, trabalharia neste campo até sua morte e influenciaria com suas aulas e com seus escritos uma legião de seguidores.

Alguns dos seus muitos seguidores, não por acaso, escrevem neste dossiê cujo enfoque temático é justamente Etnografia e Cidades, tema caro a Gilberto Velho e sobre o qual dedicou os melhores anos de sua reflexão.

Dos sete textos aqui reunidos, seis lançam mão de referenciais teóricometodológicos criados por Velho para levar a cabo suas etnografias, razão pela qual esta reflexão se torna oportuna.

Carolina Almeida e colegas aplicam os ensinamentos de Velho para compreender as nuances do futebol feminino. Empregam o clássico texto "Observando o familiar" (1978) além de Projeto e Metamorfose: antropologia das sociedades complexas (1999a). Talvez esta seja uma das suas maiores contribuições ao ajudar na construção de um olhar lançado sobre uma temática que rompe com a tradição da antropologia ligada às chamadas sociedades simples ou selvagens.

Beatriz Staimbach Albino e colegas investigam o trabalho de artistas de rua nos semáforos de Florianópolis e empregam Individualismo e Cultura (1999b) para compreender e explicar o significado mais profundo da prática observada.

Leandro Cisneros e colegas analisam etnograficamente clubes de prostitutas em Florianópolis, definidos como campo fechado da antropologia. Os autores empregam o conteúdo de "Observando o familiar" (1978) e "O antropólogo pesquisando em sua cidade: sobre conhecimento e heresia" (1980) no esforço de aproximar o antropólogo da sua própria cidade a partir do necessário estranhamento. O mesmo acontece com o trabalho de Charles Raimundo e colegas ao aproximarem-se do universo da umbanda em Florianópolis, 
produzindo uma abordagem etnográfica a seis mãos, olhos e ouvidos, exercitando assim a polifonia da escrita. Empregando os mesmo textos buscam extrair da obra de Gilberto Velho a ferramenta que lhes permite a construção de um texto complexo.

Letícia Cardoso Barreto e colegas, por sua vez, abordam a questão da prostituição masculina em Florianópolis. Também neste texto os autores lançam mão de "Observando o familiar" (1978) como estratégia para construir o distanciamento em relação a um objeto de pesquisa frequente no cotidiano da cidade.

Por último, mas ainda um bom exemplo de como Velho tem orientado o olhar antropológico de diferentes gerações de pesquisadores, vem o trabalho de Gabriel Luis Rosa onde o autor trata de discutir a prática de taxistas que trabalham à noite em Florianópolis lançando mão de "Observando o familiar" (1978).

Os textos abordam, assim, diferentes aspectos da antropologia urbana analisados a partir do eixo da complexidade - o que torna necessário ressaltar que, deste ponto de vista, não existem temas simples, familiares ou de pouca importância. O simples e homogêneo não existem, mas o complexo e o heterogêneo que as ferramentas de Gilberto Velho ajudam a desvendar, sistematizar e refletir.

Pelo olhar de Gilberto Velho o familiar se torna exótico e complexo, mesmo quando se trata de personagens tão conhecidos e populares quanto motoristas de táxi, artistas de rua, prostitutas e garotos de programa, praticantes de umbanda e jogadoras de futebol.

O pioneirismo de Gilberto Velho ao instituir os estudos da complexidade na antropologia é reconhecido e atestado por Hermano Vianna, seu orientando de mestrado e doutorado, em texto publicado no Blogspot, onde recupera sua relação de trabalho com o professor. "Se desconfio do simples, do homogêneo, e quero sempre revelar complexidade e heterogeneidade no mundo", afirma Vianna, "a culpa é do Gilberto".

Quanto ao pioneirismo na introdução dos estudos da complexidade na antropologia, Vianna é contundente: "Gilberto não importou ideias estrangeiras, adaptando-as às necessidades nacionais. Seu trabalho principal foi o desbravamento de um novo campo de estudos dentro da antropologia, sem similar "lá fora"'.

Gilberto Velho manifestava um refinado senso de humor intrinsecamente articulado com seu olhar antropológico na busca pelo diferente e inusitado. Isto se refletia em ousadia na escolha ou aceitação de temas a serem estudados, como revela o texto de Vianna em que homenageia seu orientador.

Por estas razões e por todas as outras que só a obra completa de Gilberto Velho é capaz de revelar é que fazemos aqui mais esta reverência ao velho mestre que continuará vivendo nas referências em nossas atuais e futuras antropológicas reflexões. 


\section{HUMANAS}

\section{Referências bibliográficas}

VELHO, G. Observando o familiar. In: NUNES, Édson de Oliveira (org.). A aventura sociológica: objetividade, paixão, improviso e método na pesquisa social. Rio de Janeiro, Zahar, 1978. p. 36-46.

VELHO, G. O antropólogo pesquisando em sua cidade: sobre conhecimento e heresia. In: VELHO, G. (Org.). O desafio da cidade: novas perspectivas da antropologia brasileira. Rio de Janeiro: Campus, 1980, p. 13-20.

VELHO, G. Projeto e Metamorfose: antropologia das sociedades complexas. $2^{\mathrm{a}}$ ed. Rio de Janeiro: Jorge Zahar, 1999a. p.137.

VELHO, G. Individualismo e cultura. Rio de Janeiro: Zahar, 1999b. p.152 . 